\title{
Reforma sanitaria: fundamentalismo neoliberal autoritario o democratización inaplazable
}

\author{
Sergio Arturo Cañas López
}

1. El proceso político de implantación de la reforma sanitaria en El Salvador

Toda propuesta de reforma sectorial demanda ser reconocida como un proceso político calificado de alto rango ${ }^{1}$. Ciertamente, en cuanto tal, no asume necesariamente una trayectoria lineal, lógica y racional, por lo que más bien se le caracteriza como plagado de avances y retrocesos, rupturas y continuidades, recordándonos que la propuesta en tanto proceso es esencialmente un "constructo social" que está dándose y nunca está dado; siendo precisamente por esto último que se impone la necesidad de que su abordaje obligadamente sea desde la ciencia política y no sólo desde la gerencia pública, como usualmente se lo quiere hacer ver para ungirlo de la siempre pretendida neutralidad política.

En el desarrollo de procesos políticos como la reforma sectorial, suele distinguirse los siguientes momentos ${ }^{2}$ :

i) Puesta en agenda

ii) Formulación política

iii) Adopción (decisión)

Reforma sanitaria: fundamentalismo neoliberal autoritario o democratización inaplazable 


\section{iv) Implementación y}

v) Evaluación.

En cada uno de ellos se precisa de la participación social de los actores que, en razón del proceso político en cuestión, deben ser sus protagonistas. Participación en la que los actores deberán conciliar intereses y propósitos, para la búsqueda de un proceso concertado que responda a favorecer con equidad las soluciones a los graves problemas sanitarios de la población; participación que, asumida como estrategia necesaria e insoslayable, deberá constituir un escenario en el que los diferentes actores estarán en capacidad de discutir y llegar a la toma de decisiones con base en el particular ejercicio del poder que les coloca a cada uno de ellos en la capacidad de negociar y concretar en un mismo escenario la construcción socionatural ${ }^{3}$ de la salud como expresión de la realización colectiva de los salvadoreños, en tanto sean satisfechas sus necesidades humanas fundamentales ${ }^{4}$, y en tanto se cuente con las acciones especializadas del sector salud correctamente reorientado por una propuesta de reforma que sea a la vez reivindicativa, democrática y con enfoque público ${ }^{5}$.

Con todo ello en mente, resulta interesante dedicar nuestra atención al análisis de cómo ha discurrido desde sus inicios el proceso de reforma, focalizándonos en este apartado en las importantes y no menos preocupantes dificultades que ha tenido la participación social ciudadana en un escenario en donde continuamente se ha excluido toda posibilidad de genuina participación de los actores sociales relevantes que no sea aquella que pueda mantenerse tutelada por la orientación de una política neoliberal fundamentalmente animada en lo económico por la lógica perversa de producir indigencia; decantando, además, hacia ella a sectores cada vez más mayoritarios de la población, para que luego su política social sólo proporcione una oferta restringida de servicios que lejos de resarcir los efectos de la depauperización, contribuye a agravarlos, luciendo más bien como brindadas en consolación por la condición de indigencia padecida ${ }^{6}$.

Ciertamente, en el contexto de la reforma pretendidamente impulsada en el país, el Ministerio de Salud Pública y Asistencia Social (MSPAS) definió desde hace casi una década, tres fases de lo que denominó como proceso de modernización ${ }^{7}$ : 
i) Modernización institucional del Ministerio de Salud (19951999)

ii) Modernización del Sector Salud (1999-2004).

iii) Consolidación del proceso de Modernización del Sector Salud (2004-2009).

Conviene acá destacar dos cosas: a) el uso del término modernización no tuvo en aquel entonces otro propósito más que el de contar con un término que favoreciera un manejo ideológico capaz de descalificar cualquier resistencia que este proceso llegase a despertar; de hecho, resulta fácil señalar como retrógrada toda oposición a aquello cuyo propósito no es más que "el ir con los signos de los tiempos"; y b) existe una curiosa coincidencia entre la duración establecida para cada fase y los períodos presidenciales, de forma tal que es posible inferir de ello un tomar las providencias de forma que la oposición prevista a una reforma sanitaria neoliberal significara costos políticos repartidos para los correspondientes poderes ejecutivos y sus respectivos titulares del ramo en cada quinquenio.

Una y otra de las cosas arriba señaladas es en parte lo que ha permitido, al amparo de la modernización, ir, más bien, "deslizando la reforma", procurando suscitar la menor resistencia, procurando conseguir la tolerancia requerida y hasta el beneplácito deseado; pero, en caso de oposición, repartir los costos.

Desde entonces, hasta fines de 2000 , la reforma sanitaria fue puesta en agenda y buscó quedar formulada en la propuesta oficial ${ }^{8}$. Lo primero fue más producto de lo insostenible que resultaba seguir igual cuando el sistema mismo se mostraba claramente insolvente ante el panorama sanitario que ya se sufría para entonces; cualquier actitud contemplativa era de por sí una insolencia con costos político-sociales que había que intentar reducir. En lo segundo, es decir, en el momento de formulación de las políticas, es donde, mediante doce iniciativas que lograron ser reconocidas con diverso grado de elaboración', pudo constatarse la activación de un vigoroso proceso de elaboración de propuestas por parte de diversos actores sociales en reacción a la original propuesta ministerial de 1997, aún y cuando dicha activación no correspondía a una apertura similar de espacios de concertación y construcción de consensos. 
Ciertamente, de diciembre de 1997 a diciembre de 2000, hubo alguna que otra reunión; en cada foro fue reeditado el debate, pero nunca se llegó a concretar la competencia decisoria de los actores sociales involucrados. Se oyó, se tomó nota, mas no se escuchó ni se actuó en consecuencia. De otra manera, no se explica la existencia de una Propuesta de Reforma Integral de Salud, que ministerialmente es asumida y divulgada como "la propuesta", con la que se dice reivindicar la comparecencia y el concurso de la participación social, a la vez que es de sobra manifiesta la oposición de la sociedad civil a su ejecución y los no pocos señalamientos a su contenido que, basados en evidencia, se hacen desde la perspectiva académico-universitaria, entre los que se destacan los resultados privatizadores a los que nos conduciría su aplicación ${ }^{10}$. Se consultó, intentando legitimar una propuesta de reforma que era una clara concreción de la política social neoliberal, aunque ello recibió el veto de quienes no ven en ella una representación de sus intereses. Se patrocinó el debate para burlar la participación ciudadana, se siguió - fundamentalmente - una lógica instrumental cuando se convirtió la consulta en un artefacto para intentar agilizar la llamada consolidación de la modernización del sector salud, que, en realidad, era la reforma neoliberal del mismo.

De hecho, la propuesta contenida en el documento de diciembre de 2000 ha sido presentada para jugar ese papel. De hecho, se constituye desde el ejecutivo un Consejo de Reforma para que presente su propuesta, la que esgrimida como la postura oficial, sirvió para "limpiar la mesa" de todo ejercicio previo de participación ciudadana y establecer sin más un nuevo "punto cero" como para que toda nueva discusión sea, de inicio, tutelada a partir de los lineamientos generales en ella contenidos.

Es más, tan así es la cosa que la instancia propuesta por el Consejo de Reforma para ser garante de difundirla y abrir los espacios de debate y consulta que permitan — según se consigna ${ }^{11}$-alcanzar su viabilidad social y política, así como su factibilidad técnica y financiera, lleva justamente por nombre el de Comisión de Seguimiento de la Reforma, la que en este marco de condiciones no será más que la instancia oficial de instrumentación de la reforma neoliberal que se persigue imponer en el país. El Consejo propone y la Comisión da seguimiento, en tanto el Ministerio puede incluso "hacer lucir" una 
distancia de autoría al momento de tener que enfrentar las resistencias que ella suscite.

He aquí un ejemplo más de cómo apelar a la participación social tiene diversas razones o justificaciones según sea la racionalidad particular que la sustente o la intencionalidad con que se le anime. Si ésta es perversa, será más bien para negar la competencia decisoria y capacidad resolutoria de los actores sociales y si unido a ello es parida como iniciativa dentro de un contexto de autoritarismo marcando asimétricamente las relaciones de poder entre Estado y sociedad civil, entre instituciones y población, entre prestadores y usuarios de los servicios, entonces no hay espacio para duda, la transformación de los sujetos en utensilios del quehacer de instituciones y la funcionalización de la participación constituyen una nueva tropelía, pues es un atropello evocar el debate y participación social ocurridos en 1998 y 1999 para imponer, con abuso de poder, "un borrón y cuenta nueva" e ir a lo que sigue: implantar (distinto de implementar) la reforma neoliberal, injertarla con autoritarismo, cooptando y coaccionando en favor de ella así sea requerido según las circunstancias.

El contexto en el que se pretende implantar la reforma neoliberal le resulta propicio en múltiples terrenos: se han tomado providencias han sido tomadas principalmente en lo político, ideológico, cultural, institucional y en lo legal, a veces sin poderse definir un solo campo específico de su aplicación para algunas de estas medidas. Por ejemplo, la cultura política autoritaria de algunos de los principales actores político-sociales del país, la cual aflora con fuerza ante la posibilidad de que haya alternancia en la Presidencia de la República, no sólo pone en peligro de reversión al procedimiento electoral mismo sino que a la mayoría de las novedades institucionales introducidas por los Acuerdos de Paz. Pareciera que la democratización tiene límites que no será fácil superar; la cuestión es que si no son superados, el autoritarismo gana terreno y la democratización se revierte ${ }^{12}$. De hecho, cuando las élites se muestran reacias a aceptar el principio de la alternancia en el poder, por mucho que defiendan la democracia, en realidad son una amenaza para la estabilidad política que dicen defender. Al no aceptar este principio, condición indispensable del régimen democrático, demuestran no haber entendido (o no querer entender) su esencia. De no respetarla, habría una dictadura personal o partidaria en la práctica. Eso es lo que pretende implantar la derecha salvadoreña.

Reforma sanitaria: fundamentalismo neoliberal aułoritario o democratización inaplazable 
Esta movilización (autoritaria) de la derecha encierra otros peligros para el sistema político. Uno de ellos es la polarización del Estado y de la sociedad que lleva de manera inexorable a la crisis de gobernabilidad. La polarización está llevando a cerrar cada vez más la apertura política recién estrenada, hace una década. Cada vez hay menos espacios para discernir del poder, lo mismo en los partidos, que en el Estado, o en la sociedad en general. La intolerancia gana terreno a medida que se endurecen las posturas. El cierre del espacio político y social es palpable ${ }^{13}$.

Pero el autoritarismo es un fenómeno que no sólo afecta las relaciones políticas; en tanto fenómeno cultural tiene manifestaciones en los más diversos ámbitos de la vida nacional, comenzando desde el mismo sistema familiar donde se toman decisiones que afectan a todo el grupo familiar, hasta el sistema político, donde se toman decisiones vinculantes para la sociedad en general. En el campo de las políticas públicas, también es notable el predominio del comportamiento autoritario. Las políticas entendidas aquí como productos del sistema político, como decisiones y acciones contempladas en ellas, muestran la impronta autoritaria. A ningún observador de la política salvadoreña escapará la forma autoritaria como se adoptó la decisión de dolarizar la economía. Siendo una decisión de trascendencia para la nación, la medida se aprobó sin mayor discusión pública. La Ley de Integración Monetaria no sólo implicó la circulación legal de la moneda estadounidense en El Salvador, sino que cedió (sin más) una parcela de la soberanía nacional que proclama la Constitución ${ }^{14}$.

Obviamente, el autoritarismo, junto a las manifestaciones ya comentadas, está adquiriendo nuevas particularidades que requieren análisis, particularmente en el ámbito ideológico-cultural-institucional y en el ámbito legal. En el primero, analizaremos el manejo hecho de la llamada Rectoría de la Salud atribuida al Ministerio de Salud en momentos de reforma sectorial y en el segundo, las implicaciones del recién presentado anteproyecto de Código de Salud, precisamente en septiembre de 2003. 


\section{La correcta comprensión del concepto de rectoría de la salud}

La propuesta de reforma presentada pretende la reorganización y reestructuración de las instituciones del sector salud, lo que incluye: una reestructuración funcional del Ministerio de Salud que le permita adoptar un rol normativo regulador, facilitador y financiador propio de la función rectora; y una descentralización de los sistemas programático y administrativos de salud, con la transferencia de las funciones de planeamiento, administración, obtención y asignación de recursos para la provisión de servicios desde el nivel central hacia las otras instancias públicas y privadas.

El fortalecimiento de la función rectora obliga, para su análisis, a una precisión conceptual que permita ver en qué consiste, cómo se le debe entender, cómo se le entiende y qué significa de cara al fomento o restricción de la participación social en el diseño de la política pública en salud sobre la cual descansará la reforma.

Por su parte, un ejercicio similar lo demanda el análisis riguroso de la descentralización que se propone bajo la modalidad de desconcentración técnico-administrativa (departamentales de salud/ Sistemas Básicos de Salud Integral, SIBASI), y de la delegación en la provisión mixta de servicios entre entidades públicas y privadas. Estando ya ambos análisis muy consistentemente desarrollados por Selva Sutter ${ }^{15}$, dediquémonos al análisis de la rectoría.

Delimitados ya en el primero de los puntos (Fortalecimiento de la Función Rectora) diremos de inicio que en momentos tales como el presente, de formulación política e inicio de la adopción de decisiones trascendentes, el buen curso de la reforma de salud demanda comprensión correcta y buen uso de concepto de Rectoría de Salud, concepto prismático cuyo entendimiento —no siendo unívoco- provoca entrampamientos peligrosos e imprecisiones en los términos de referencia de la relación entre el Ministerio de Salud y sus contrapartes en tanto expresión concreta de la relación Estado/Sociedad Civil en la que obviamente queda inscrita la primera.

Por definición, se ha dicho siempre que la rectoría de salud es un papel que corresponde al Estado dada su responsabilidad constitucional de velar por la salud de la población, su papel redistributivo de la riqueza nacional y su presupuesta función reguladora de la actividad privada en beneficio social. Ciertamente, ello hace referencia a que

Reforma sanitaria: fundamentalismo neoliberal autoritario o democratización inaplazable 
son los Ministerios de Salud, en tanto referentes del Estado, los llamados a ejercer la rectoría sectorial a la que se hace referencia.

Ahora bien, también está descrito que la efectiva rectoría institucional en el sector salud implica ${ }^{16}$ :

- Representatividad del Estado en materia de salud.

- Manejo efectivo de otros recursos de poder como:

-Influencia política.

- Capacidad técnica.

- Manejo de recursos financieros.

- Poder de convocatoria y capacidad de negociación.

Para que el Ministerio de Salud pueda cumplir a cabalidad los elementos anteriores, debe tener capacidad de liderazgo, donde use la excelencia del conocimiento científico y tecnológico junto con la capacidad de comprender toda la complejidad de la inserción de salud en el proceso social: sea ya creando espacios, promoviendo iniciativas y generando condiciones para que la producción social de la salud sea un componente fundamental del desarrollo del país.

Se está diciendo, entonces, que una efectiva rectoría institucional no sólo necesita capacidad de gestión (competencia para dirigir, administrar, tomar decisiones), normativa (conferir a un acto carácter jurídico), de regulación y de aseguramiento de la provisión de servicios. Se precisa, cuando menos, de dos condiciones de viabilidad particularmente requeridas en momentos en que la reforma misma aspira lograr el fortalecimiento de esa rectoría por parte del Ministerio: (1) Liderazgo, en tanto acumulación de prestigio político y técnico generado del conocimiento de la situación y de las actuaciones coherentes con tales prestigios ante los procesos de reforma y (2) Habilidad en el manejo de coyunturas, en tanto que son estos los momentos-síntesis del proceso político que supone la reforma sectorial.

La cardinal importancia de estas dos condiciones de viabilidad para una efectiva rectoría institucional queda aún más destacada cuando de entre las conocidas como funciones de la rectoría en la producción social de la salud (PPS) se destacan la dirección y conducción política de la salud ${ }^{17}$. 
La función de dirección estriba en la capacidad de definir objetivos viables y metas factibles de alcanzar en salud, concretada esta acción en el acto de formular la política nacional de salud sobre la base de las discusiones y decisiones con los actores sociales participantes en el proceso de su formulación; una vez formulada la política se constituye en el marco general regulatorio para la organización y gestión de los servicios. En tanto que conducción en el marco de la rectoría es la capacidad para concretar intereses, movilizar recursos y coordinar acciones de las diferentes instituciones y actores sociales para dar cumplimiento a la ya formulada Política Nacional de Salud.

Ni una ni otra condición de viabilidad parecen estar presentes y ninguna función de rectoría se está cumpliendo efectivamente. De hecho, de un análisis del mapa de actores y procesos políticos activos hasta diciembre de 2000 , permite concluir que la promoción de la reforma por el Ministerio de Salud fue conducida de forma tal que generó más confrontación que concertación y consenso. La conflictividad laboral expresada en las huelgas ocurridas del $2000 \mathrm{al}$ 2003 lo ratifican. El debate pospuesto tenderá a reeditarse ahora con la Comisión de Seguimiento, muy probablemente con posterioridad a las elecciones de marzo.

Así las cosas, ciertamente es requerido un urgente y enérgico giro en el proceder del Ministerio; y es que si algo es cierto es que el nombre del juego en este proceso político que implica la reforma no puede ser otro que negociación para alcanzar el consenso que le de viabilidad política a aquella.

Es requerida, entonces, una participación en democracia para el diseño e implementación de las políticas públicas, en donde los conceptos de Estado, participación, gobernabilidad, etc. aparecen como palabras claves de una dimensión democrática más profunda que deben adquirir nuestras sociedades si es que se quiere asegurar que políticas públicas estén vinculadas a ciudadanía; es decir, a la intervención de particulares en actividades públicas, en tanto portadores de intereses sociales y en complementación a la democracia representativa ${ }^{18}$.

Aparte de la gobernabilidad, que supone alcanzar una política social concertada, a su viabilidad política (de la reforma) también contribuye el que pueda llegar a constituirse en política de Estado; ello constituye el mejor antídoto contra los frecuentes cambios de direc-

Reforma sanltaria: fundamentalismo neoliberal auloritario o democralización inaplazable 
ción a que están expuestas las políticas de salud por el simple arbitrio de un golpe de timón de la autoridad de turno.

Es en este terreno donde cobran fuerza las expresiones de que lo estatal no se agota en lo público y que hay, por lo mismo que fortalecer a la sociedad civil frente al Estado, construyendo ciudadanía; porque es precisamente así como la participación ciudadana encuentra su específico terreno en la gestión pública: como forma de mejorar su funcionamiento ${ }^{19}$ y de refrendar su condición de perteneciente al pueblo.

Caso contrario, cuando la administración pública se apropia excluyentemente de las decisiones de la política pública y de su implementación, no sólo atropella la soberanía como fundamento declarado del régimen democrático, sino que convierte la "cuestión pública" en "cuestión de expertos", lo que está sucediendo precisamente con la creación de la Comisión de Reforma del Sector Salud y su Propuesta de Reforma Integral de Salud y, más aún, con la Comisión de Seguimiento sugerida en dicha propuesta ${ }^{20}$.

Una cosa es cierta: Cuanto más fluida sea la relación del Estado con los ciudadanos, las instituciones estatales serán capaces de ganar efectivamente legitimidad ciudadana: ello es así, dado que en el propio corazón de la gobernabilidad, se instala día a día el tema de la ciudadanía y, por ende, el de la participación. Ciertamente, un Estado demasiado regulado y que tenga establecido un monopolio completo en la ejecución de los servicios, no tiene espacio para la participación, sino que solo para la demanda. En contrario sensu, un Estado en el que se articulen de otro modo lo estatal, y lo ciudadano, crea efectivamente intersticios para la participación en el diseño, ejecución y evaluación de las políticas públicas; en resumen, será un Estado que constituye ciudadanía ${ }^{21}$.

Así planteadas las cosas, el dilema sectorial en El Salvador es: democratización inaplazable o autoritarismo.

\section{La cultura institucional y diseño organizacional del Ministe- rio: su contribución a la implantación de la reforma bancomundialista}

Hablar de Estado obliga a distinguir entre aparato de Estado y poder del Estado. Se dice que el poder del Estado lo tiene la clase, las 
fracciones de clase o la alianza de ellas que detenta dicho poder para poner el aparato de Estado en función de sus objetivos o intereses estratégicos ${ }^{22}$.

Ahora bien, el posterior progreso y desarrollo más acabado de la teoría del Estado ha permitido distinguir más bien al aparato del Estado como constituido por dos tipos de ellos: aquellos que funcionan fundamentalmente con el uso de la fuerza, o al menos al límite de ella (aparatos represivos del Estado revistiendo diversas formas de coerción que no necesariamente adquieren formas de violencia física) y, por el otro lado, los aparatos ideológicos del Estado que no son más que un diverso número de realidades o instituciones que acostumbran no siempre presentarse a primera vista como relacionadas con el Estado y mucho menos como funcionando para procurar cohesión-consenso en torno al proyecto político de quienes detentan el poder del Estado. Actúan, pues, presentándose muchas veces como instituciones más bien especializadas y, en mucho, en tal especialización “ocultan" la relación con su papel esencial de contribuir desde ella a dar viabilidad a un determinado estado de $\cos ^{23}{ }^{23}$.

Aún cuando el Ministerio de Salud, con todos sus establecimientos, podría identificarse más descriptivamente con su función especializada de "velar por la salud", pareciendo nada tener que ver con acciones que permitan identificarlo como aparato ideológico del Estado, lo cierto es que cumple en rigor las características de estos.

Adicionalmente, una característica singular de los aparatos ideológicos del Estado es que, contrario a los aparatos represivos del mismo, dan muestras más claras de la diversidad o pluralidad de los mismos, de forma tal que no es fácil conceptuarlos, ni advertir su condición de conjunto, como visible a primera vista, a más de que no tienen por qué pertenecer todos ellos forzosamente al dominio público; así el mosaico de aparatos ideológicos del Estado incluye, entre otros, al aparato religioso, escolar, familiar, informativo, cultural, sanitario, etc.

Su carácter unitario, su carácter que los hace formar parte de un solo y mismo conjunto, es el hecho categórico de que funcionan promovidas al amparo del Estado y promoviendo sus servicios, teniendo por propósito no siempre o casi nunca declarado, el de cohesionar para viabilizar de una u otra manera (según el servicio que presten) la

Relorma sanitaria: fundamentalismo neoliberal autoritario o democratización inaplazable 
reproducción misma de la estructura de poder que se ejerza sobre determinada realidad social24. En resumen, cada quien toca su instrumento interpretando la misma partitura.

Esto nos lleva al punto del papel que en el sistema sanitario, en tanto aparato ideológico del Estado, juega el personal del Ministerio, papel que resulta más diáfano en el particular contexto de reforma sectorial. Ciertamente, los aparatos ideológicos del Estado requieren para serlo de la presencia y acción de quienes como funcionarios de la superestructura ${ }^{25}$ tratan de lubricar el consenso que resulte necesario para mantener la hegemonía del bloque histórico que permanece en el poder o instigar a favor del mismo, cooptando disensiones, invocando a la rectoría en salud de la que está investido el ministerio por el hecho de serlo, por su condición de secretaría de Estado y no por su liderazgo y habilidad para el manejo de coyunturas en la dirección y conducción políticas del sector, particularmente en el contexto de la reforma.

Si la participación ciudadana se desborda del tutelaje previsto, los funcionarios aplicarán una variedad de procedimientos que van desde instar, urgir, apremiar, cooptar, hasta emplear la coacción, para conservar la dirección del proceso antes que escape de las manos en un ir y venir entre autoritarismo y democracia de baja intensidad.

Que se tienda a requerir más la coacción en estos momentos es una experiencia repetida cada vez que en el país se ha entrado a una reformulación estatal del proyecto de dominación. Ciertamente, con la reforma sanitaria neoliberal lo que en el fondo se propone es implantar una nueva lógica como principio ordenador del sector salud en su conjunto: la lógica del mercado. Asistimos a un proyecto global de reorganización de la sociedad con una concepción precisa sobre cómo satisfacer las necesidades sociales que implica una reestructuración profunda de lo público y la constitución de beneficios y servicios sociales en el ámbito directo de la acumulación de capital. La concepción de esta política en el ámbito de los servicios de salud está plasmada paradigmáticamente en el documento Invertir en salud, elaborado por el Banco Mundial26, en el que se introduce de manera sugestiva una serie de argumentos y propuestas que, luciendo a primera vista técnicamente consistentes y razonablemente atendibles, en el fondo hay que develar más a detalle sus resortes internos para po- 
der señalar que sus promesas de equidad, cobertura, eficiencia y calidad son sólo eso: promesas; y que contrariamente a ello, Invertir en salud está más bien diseñado para denegar servicios de salud a los segmentos cada vez más empobrecidos de El Salvador. En resumen, la nueva política social tiene como propósito central trasladar el control sobre los fondos sociales al capital privado. Esta apropiación indebida de los bienes de la sociedad se advierte claramente nociva para las mayorías populares cuando el Estado deja el terreno libre al capital para que este opere en este campo, creándole condiciones que le generan beneficios extraordinarios ${ }^{27}$.

Tener esto particularmente claro es importante en un país como El Salvador, en donde se ha aceptado con credibilidad todos los dictados de la doctrina neoliberal y donde sus políticas han sido aplicadas con bastante rigurosidad, con base en la confianza que los gobernantes todavía tienen en que la globalización en sinergia con el neoliberalismo llevarán a la prosperidad y al deseado desarrollo sostenible. Ciertamente, el neobieralismo, tal como se entiende en América Latina, es una concepción radical del capitalismo que tiende a absolutizar el mercado hasta convertirlo en el medio, el método y el fin de todo comportamiento humano, subordinando la vida de las personas, el comportamiento de las sociedades y la política de los gobiernos ${ }^{28}$.

Esta concepción asumida con disciplina y entusiasmo tan militantes, ha hecho señalar que el fundamentalismo es una de las más recientes manifestaciones del escenario de crisis mundial aún no resuelto - más aún, empeorado- por la aplicación universal y uniforme de las políticas neoliberales. Floreciendo en tiempos de crisis y de ambición de poder, el fundamentalismo otorga seguridad y carácter absoluto a los intereses particulares, llega a otorgar carácter absoluto con validez universal a su necesidad de sobrevivencia o a su interés por mantener su poder, que traza así una frontera infranqueable entre quienes están dentro y quienes permanecen fuera, consolidando la cultura de la exclusión ya descrita. El convencimiento absoluto acerca de la validez de lo propio lleva implícita la intolerancia y la inflexibilidad que caracteriza la praxis fundmentalista que sin miramientos domina excluyendo ${ }^{29}$.

En ese contexto de fundamentalismo neoliberal autoritario es que al personal del Ministerio le toca jugar el papel de funcionarios de la superestructura, impulsando la reforma bancomundialista, y la cultura

Reforma sanitaria: fundamentalismo neoliberal aułorilario o democratización inaplazable 
institucional del Ministerio sirve para que sus miembros lleguen a comprender las formas de conducta que resultan apropiadas en la institución y en consecuencia, la conducta que se espera de ellos a propósito de la reforma. Así, la cultura institucional sirve de mecanismo de control y lógica que guía y da forma a la conducta de los empleados haciendo que actúen de manera relativamente uniforme y previsible. De suyo, la cultura institucional no puede ser juzgada como mala por el mero hecho de existir; se convierte en un peso cuando se trata de constituir como sistema de valores y significados de los que no se puede esperar conseguir identidad de sus miembros sin preocuparse por evocar la aplicación de normas y reglamentos para guiar la conducta de sus empleados.

Acá es donde queremos referirnos a la contribución de Michel Foucault al estudio de la dominación desde la óptica de la complejidad de las relaciones de poder, la dispersión de sus fuentes y la particular relación entre consenso y coerción por él planteada. Estos problemas son especialmente analizados en su obra Vigilar y castigar ${ }^{30}$, en la que el autor intenta demostrar que en el proceso de creación y reproducción de las instituciones consensuales contemporáneas, está invariablemente presente la sutil violencia de la disciplina; elemento determinante del comportamiento humano. De acuerdo con Foucault, en las instituciones sociales los individuos están sujetos a un constante y meticuloso control de sus operaciones ${ }^{31}$. De tal forma, lo que Gramsci llamó consenso, desde el punto de vista foucauliano es alcanzado por la violencia de la disciplina. En la dominación a través de mecanismos disciplinarios, sujetos y objetos de control se confunden pues, frecuentemente, un mismo individuo experimenta ambas situaciones en diferentes circunstancias. Ello es manifiesto hasta en aquellos espacios donde el poder se esconde tras la fachada de la "neutralidad" de instituciones sociales como hospitales y asilos ${ }^{32}$.

De acuerdo con Foucault, es posible entonces desnudar importantes instrumentos de control social que se ocultan en las instituciones en donde la mayoría del personal sanitario se forma, caracterizadas por la verticalidad y jerarquización típicas de los servicios e instituciones de salud donde las decisiones ruedan desde la cúpula hacia abajo. Su estructura piramidal conformada sobre la base de la especialización del saber, la centralización excesiva que le acompaña y la ausencia o precaria cultura institucional participativa caracterizada por 
una pobre tolerancia al conflicto, que se refleja en el escaso grado en que se fomenta que los empleados traten abiertamente sus conflictos, críticas y señalamientos a la institución y a su trabajo, allanan el camino para que el fundamentalismo neoliberal autoritario sea ejercido sobre el personal al interior de las estructuras ministeriales.

El trabajador sanitario sentirá con absoluta razón que las tareas burocráticas le agobian, que en ocasiones le restan tiempo de dedicación a la asistencia, que ellas en mucho son instrumentos de control de la gerencia sobre su trabajo, no necesariamente motivado por ser visto como presunto transgresor siempre bajo sospecha, sino por otros factores que entran en el terreno de la teoría mintzberiana del diseño organizacional según la cual se está frente a una burocracia profesional ${ }^{33}$ en la que forma parte de un núcleo operativo o de la línea media, según realice el trabajo especializado de la atención sanitaria o conecte a ese núcleo operativo con el ápice estratégico que tiene la responsabilidad global de la institución. Las competencias de cada cargo están plenamente establecidas existiendo para ello una importante proliferación de reglas y normas surgidas de la tecnoestructura y la autoridad es de tipo jerárquico (poder según posición).

Entonces, la burocracia profesional mintzberiana que encontramos en el Ministerio de Salud no puede ser más que el mejor tipo de estructura organizacional para que el fundamentalismo neoliberal autoritario active sus engranajes y correas de transmisión a ser lubricadas a fuerza de disciplina, en donde el ápice estratégico hace cumplir "rodando hacia abajo" lo que la reforma bancomundialista prescriba.

\section{La rectoría y el nuevo Código de Salud}

En septiembre de 2003, la Asamblea Legislativa presentó el Anteproyecto de Código de Salud, entre cuyos considerandos se consigna "que es necesario dar respuestas a realidades sociales concretas y que en virtud de ello se debe contar con un documento legal en el que se privilegie la rectoría, la promoción y la prevención, la atención primaria de salud y la participación social, y se creen las condiciones necesarias para dar cumplimiento a lo establecido en la Constitución de la República"34.

Reforma sanitaria: fundamentalismo neoliberal autoritario o democratización inaplazable 
Desde el inicio (en el apartado sobre el objeto y ámbito de aplicación del Código), y en posteriores títulos y capítulos del anteproyecto, se explicita la participación de instituciones públicas, autónomas y privadas como constituyentes del sector salud, "las que tendrán las atribuciones y funciones que les asignen las leyes, reglamentos, ordenanzas y estatutos respectivos, bajo la rectoría del Ministerio"35. Llama poderosamente la atención la inclusión de "las municipalidades a través de los programas de servicio de salud" como uno de los integrantes del sector ${ }^{36}$, pues eso puede dejar abierta la puerta, dada la rectoría, a que responsabilidades de los servicios de salud, incluida la atención, sean transferidas a las alcaldías al amparo del marco legal que el código produce. De hecho, ello ya ha venido sucediendo en casos aislados, aun cuando ello supone ir más allá de lo que son la actuales competencias municipales. Las que hasta hoy son contribuciones -en algunos casos importantes dado los presupuestos de las alcaldías - logradas por acuerdos interinstitucionales pactados a nivel local, podrían ser exigidas con fuerza de ley dado este código. Esta preocupación, difícilmente es infundada; de hecho, la asignación del $8 \%$ a las alcaldías ha generado el forcejeo político en medio del cual ya se aceptado el otorgar el $2 \%$ adicional, pero a cambio de cargar con responsabilidades sanitarias a las alcaldías. Es decir, se asigna la partida en cuestión, pero a cambio de transferir la responsabilidad a una entidad ejecutora ya establecida.

Aparte de ello, queda también establecido en el Código que el llamado Sistema Nacional de Salud tiene por objeto, bajo la rectoría del Ministerio, hacer accesible los servicios de atención a la salud que demande y requiera la población, facilitando su uso más justo, eficaz y eficiente, propiciando esfuerzos de coordinación e integración del sector público, autónomo y privado, lucrativo o no, para mejorar el desempeño en la provisión de servicios y garantizar la optimización de los recursos en materia de salud" ${ }^{37}$. Ambas definiciones - de sector y Sistema de Salud- permiten concluir la opción por un sistema mixto previsto para ser implementado por la orientación bancomundialista que fundamenta la Propuesta de Reforma Integral de Salud ya comentada acá y analizada en extenso por Selva Sutter, quien señala las razones por las que no puede ser opción y los riesgos que su constitución implica ${ }^{38}$. 
Tanto en el sistema como en el sector, el Ministerio será el ente rector del sistema mixto teniendo por funciones ser "responsable de los procesos de regulación, planificación, definición y ejecución de la política nacional de salud" con cuarenta y cinco atribuciones detalladas ${ }^{39}$, entre las que destacamos diez para los propósitos de este escrito:

1. Ejercer la rectoría de la salud;

2. Cumplir y hacer cumplir el presente Código, los tratados internacionales ratificados, leyes, reglamentos y demás disposiciones legales y técnicas relacionadas con la salud;

3. Impulsar el desarrollo del Sistema Nacional de Salud;

4. Definir y orientar la política nacional de salud como parte integral de los planes de desarrollo económico y social del país;

5. Coordinar las acciones de salud que se ejecuten en sus dependencias y las del Sector Salud;

6. Establecer la estructura orgánica y funcional interna;

7. Suscribir convenios relativos a la salud, con personas naturales o jurídicas, tanto nacionales como internacionales, estos últimos por designación del Órgano Ejecutivo;

8. Crear o ratificar las comisiones que sean necesarias en el ámbito de la salud;

9. Elaborar, aprobar y divulgar las normas técnicas o administrativas y proponer leyes y reglamentos necesarios en materia de salud;

10. Ejercer el control técnico administrativo, sobre las personas naturales o jurídicas, nacionales e internacionales que realicen acciones de salud.

Nada escaparía al control omnímodo del ente omnipresente y omnipotente: el supremo. Pero ejercer rectoría sin liderazgo y habilidad en el manejo de coyunturas es estar imposibilitado para ejercer de la rectoría las funciones de dirección y conducción política; es mandar, no gobernar.

Ahora bien, de cara a la implementación de la reforma, no se puede dejar de comentar que el mismo código contempla la creación del Consejo Nacional de Salud ${ }^{40}$ como organismo técnico asesor adscrito

Reforma sanitaria: fundamentalismo neoliberal autoritario o democratización inaplazable 
al Ministerio, cuyos miembros serán designados por el Órgano Ejecutivo, luego de que la máxima autoridad de las instituciones que lo conformen proponga, a través del Ministerio de Salud, al Presidente de la República, el representante titular y suplente que lo constituyan.

Las instituciones que lo integrarán son: el Ministerio, que lo presidirá; el Ministerio de Ambiente y Recursos Naturales, el Ministerio de la Defensa Nacional, el Instituto del Seguro Social, las instituciones privadas proveedoras de servicios de salud, los usuarios de los mismos y otras instituciones que a juicio del Órgano Ejecutivo en el ramo de Salud Pública puedan formar parte del mismo.

La creación de esta instancia tendrá por funciones - entre otrasdos particularmente importantes para juzgar su competencia en el particular escenario de implantación política de la reforma: "asesorar al Ministerio en la formulación, ejecución y evaluación de políticas y estrategias para el desarrollo de programas y planes nacionales de salud" y "emitir dictámenes técnicos a solicitud o en coordinación con los titulares, que podrán relacionarse con revisiones de estructuras, funciones y estrategias que plantee el Ministerio para el mejor logro de sus objetivos y metas". En tanto que su organización será establecida en su reglamento, así como la idoneidad de los que lo conformen, quienes actuarían con carácter ad bonorem por un período no mayor de cinco años, no reelegibles ${ }^{41}$.

Es obvio, que acá estarían los que gocen de la confianza del presidente y ministro de turno. Aquí la pretendida idoneidad significa gozar de la mayor confianza de los altos funcionarios, lo cual es un requisito, dadas las decisiones que la implantación de la reforma requerirá de acá en adelante.

Entonces, esta introducción de una nueva instancia en el tinglado de poder del Ministerio podría constituir parte de ese "poner a punto la máquina", que hemos venido analizando.

\section{Participación y contraloría social en el SIBASI y en el nuevo Código}

Ya en la presentación de la versión revisada del marco conceptual y operativo de los Sistemas Básicos de Salud Integral ${ }^{42}$, estructura básica operativa del Sistema Nacional de Salud, el Ministerio deja ver 
su particular concepción de participación social y contraloría. Considerado el SIBASI "piedra angular de la modernización, insumo en el proceso ineludible de la Reforma del Estado"43, este modelo de gestión descentralizada apela al principio de corresponsabilidad ${ }^{44}$ que conduce a la identificación de actores sociales y a su participación en la problemática de salud, a la cual le señala únicamente una "dimensión comunitaria, municipal y, o departamental ${ }^{45}$; y, en tanto ente gestor y proveedor, el SIBASI comprende en su estructura organizativa tres elementos: el gerencial, la consulta social como expresión de la participación social y los proveedorés de los servicios de salud ${ }^{46}$. De hecho, su organigrama ${ }^{47}$ refleja la existencia de un Comité de Consulta Social, atendiendo al elemento de participación social.

Al definir los componentes fundamentales del SIBASI, la participación social está considerada la estrategia dentro del sistema que si bien declara tener por propósito "el fortalecimiento de la conciencia crítica de la población para mejorar los procesos de toma de decisiones en la solución de los problemas de salud y el autocuidado"48, lo interesante resulta al conocer los tipos de participación social que dentro del SIBASI pueden ser. Para iniciar, los primeros tres tipos (participación pasiva, participación informativa y participación consultiva) ni siquiera son eso, sino más bien su claros antónimos: ejecutar acciones a solicitud del personal de salud, sin intervenir en la toma de decisiones; establecer interacción con el usuario informante, el cual no tiene acceso sobre los usos que los establecimientos puedan dar a la información brindada; consultar el punto de vista sin que pueda llegarse a tener incidencia alguna sobre las decisiones que se puedan llegar a tomar no son más que acciones antípodas a la participación y el sólo hecho de incluirlas en un documento oficial resulta en sorprendente desatino y en clara tropelía al entendimiento.

$\mathrm{El}$ asunto suma y sigue cuando los tipos restantes de participación social que pueden ser dentro del SIBASI incluyen ${ }^{49}$ la negociada (trueque de incentivos materiales, sociales, capacitaciones a cambio de trabajo, sin tener incidencia directa en decisiones del proyecto), la interactiva (participación en formulación, implementación y evaluación del proyecto que supone la toma de control en forma progresiva del proyecto) y la autoparticipación (de grupos organizados que desarrollan sus propios proyectos, buscan su sostenibilidad y solicitan asesorías concretas de acuerdo con sus actividades). Ciertamente, en las 
dos últimas se advierte un suscribirse a un esfuerzo y reivindicar la autoría y los frutos del mismo aun y cuando estos no sean referidos más que a intervenciones que no sobrepasan la complejidad de un proyecto, con la agravante que si es propio los grupos organizados no merecen acompañamiento, sino que asesorías. De la negociada, baste decir que en esencia es universalmente conocida como la que menos crea comunidad, la que menos promueve el diálogo, desata la palabra, anima la reflexión, libera el pensamiento y desarrolla el empoderamiento de las poblaciones ${ }^{50}$.

Siendo uno de los cinco componentes del SIBASI, la participación social, entendida de manera tan particular como ya lo hemos puesto en evidencia, tiene tres subcomponentes: 1) la educación en participación ciudadana y comunitaria, autocuidado de salud y autogestión; 2) la intersectorialidad y 3 ) la contraloría social. Para cada uno de ellos, el marco conceptual-operativo del SIBASI define actividades. De los primeros dos subcomponentes, destacamos acá que se procederá a "Definir los mecanismos de expresión de la participación social y de la intersectorialidad, lo cual sugiere que no puede o debe ser más que el que resulte avalado por patrocinio ministerial; y de la contraloría preferimos mejor transcribir sus actividades para que el lector juzgue su carácter esperpéntico: definir el rol de la contraloría social, definir el perfil de los miembros del Consejo de Consulta Social, definir los mecanismos para el ejercicio de la contraloría social, capacitar en el ejercicio de la contraloría social de la gestión y definir los criterios para la evaluación social de la gestión. En fin, todo deberá estar definido, nada podrá ser sin estar definido. Vaya manera de escamotear, vaya manera de aherrojar la contraloría, que de actuar de esa forma la pregunta obligada es icontraloría hacia quién? Así las cosas, lo planteado por contraloría social está adulterado convirtiéndola en policía médica ${ }^{51}$.

El nuevo Código termina de completar el cuadro de lo que, incluso ya con fuerza de ley, nos ofrecería el Ministerio en lo que a participación y contraloría respecta.

En su glosario, el Código propuesto señala la participación social como "la responsabilidad compartida de las instituciones de salud y otros sectores en coordinación con la persona, familia y comunidad en la planificación ejecución, contraloría de programas y proyectos" ${ }^{32}$. 
Llaman la atención dos cosas: la responsabilidad es coordinar y la complejidad sobre lo que se coordina no supera la de un programa o proyecto. De hecho, la participación social se supedita por completo al ámbito local. Así lo confirman los objetivos que se le asignan en el Código, como las instancias organizativas en las que contempla su realización (asambleas comunitarias, comités de salud, consejos o juntas directivas de salud y redes comunitarias) ${ }^{53}$. Cabría entender que estas instancias sean descritas en el documento que contiene el marco conceptual-operativo del SIBASI, pero su aparecimiento en el Código de Salud, es más para aherrojarla que para fomentarla a las dimensiones de nación. Es poner grilletes a una participación que así entendida jamás podrá incidir sobre cuestiones estratégicas como definir el rumbo de una reforma sanitaria. Es, sencillamente, pulverizarla en el ámbito local para atomizarla en proyectos locales, mientras lo que está en juego es la definición del rumbo.

\section{La propuesta de cogestión de la reforma: de la participación tutelada al ejercicio de la democracia participativa}

Hasta aquí hemos analizado el proceso político generado con la activación de la reforma de salud, destacando cómo la pretendida rectoría institucional al interior del sector no ha sido alcanzada fundamentalmente por la falta de liderazgo y poca habilidad que en el manejo de la coyuntura a tenido el Ministerio de Salud. Igualmente, se ha destacado cómo lo anterior ha impactado negativamente la dirección y conducción política de la salud, en tanto funciones cardinales de la rectoría en la producción social de la salud.

Procede de acá en adelante formular propuestas y acciones que, desbloqueando el proceso, permitan superar el escenario ya comentado en apartados anteriores. Para la formulación de la propuesta partimos de la acotación de las siguientes premisas ${ }^{54}$ :

a. Mientras mayor es el nivel de pluralización política, más intenso será el debate sobre la reforma sectorial y mayores las energías comprometidas en mejorar su impacto en la salud; inversamente, mientras menor la pluralización, menor será el debate público y mayor el esfuerzo competitivo entre los grupos de la sociedad desplegando cada actor sus fuerzas y recursos de poder con el fin de rivalizar y dominar la direccionalidad de la toma de decisiones.

Relorma sanilaria: lundamentalismo neoliberal aułoritario o democratización inaplazable 
b. Mientras más tecnocrático sea el proceso de formulación e instrumentación de políticas públicas, menores serán los espacios dejados a las presiones sociales para mejorar los niveles de salud; inversamente, mientras más politizado el proceso de formulación e instrumentación de la reforma del sector salud, mayores serán las presiones sociales para mejorar la reforma del sector salud.

c. Mientras más fragmentado sea el sector salud, menor será su poder de negociación frente al poder estatal central y menores las posibilidades de generar presiones conjuntas para mejorar los niveles de salud y bienestar; inversamente, mientras más integrado el sector salud, mayores las posibilidades de construir coaliciones internas capaces de presionar hacia la mejora de la misma.

Se deduce, entonces, que actuando como contrafigura de las anteriores premisas, el proceso de reforma sectorial requeriría:

- Mayor pluralización política.

- Correcto balance político-técnico en la formulación e instrumentación de la política pública.

- Mayor poder de negociación frente al poder estatal central nacido de la articulación menos fragmentada de los distintos actores sectoriales.

En resumen, el proceso requiere la construcción de un escenario tal, en el que deberá considerarse el poder de cada uno de los actores sociales; esto implica, sin duda, superar al interior del sector esa "democracia de baja intensidad" que ha sido compatible con los diversos grados y modalidades de la exclusión política en lo tocante a la formulación de la política que sustente a la reforma, para poder así establecer y consolidar una recuperación de la soberanía de los actores sociales en dicha formulación e instrumentación sin abdicar su responsabilidad ante los poderes públicos y el futuro de la nación. De hecho, el poder público ya no puede seguir ignorando que políticamente produce exclusión y que ignora - a la vez- a los excluidos que produce de continuar con el fundamentalismo neoliberal autoritario con el que ha venido actuando ante el tema de salud.

Si se trata entonces de superar esa especie de participación tutelada con que el poder público quiere administrar el protagonismo de la sociedad civil, se deberá más bien de alcanzar la cogestión de la salud 
para que la reforma sanitaria sea un lugar de encuentro, en vez de una arena de confrontación.

De hecho, si la reforma sectorial sigue siendo un proceso político en donde si no se coopta se coacciona, los ciudadanos terminarán finalmente participando aún cuando sea a través de la adopción de diversas manifestaciones de expresar su disentir.

Es ante ello que se presenta la propuesta que a continuación se fundamenta y detalla en sus elementos constitutivos:

1. Debe partirse de reconocer sin restricciones la necesidad inaplazable de entrar en un proceso de ejercicio de democracia participativa, en clara complementariedad con la democracia representativa, como parte del proceso político que supone la Reforma de Salud en El Salvador, aun cuando esto represente una situación acerca de la cual se carezca de mayor experiencia histórica en el sector salud ${ }^{55}$.

2. En tal sentido, los actores sociales que ya han formulado propuestas a propósito de la reforma sectorial ${ }^{56}$, deben buscar constituirse en el Comité de Consulta Ciudadana para la Reforma de Salud que vertebre la iniciativa de la sociedad civil, en tanto interlocutor referente contraparte del Ministerio en el proceso.

3. El Comité de Consulta Ciudadana así constituido deberá tener por competencia convocar a un plebiscito ${ }^{57}$ sobre los aspectos más relevantes de la reforma, para lo cual debería organizar el Congreso de Consulta Ciudadana para la Reforma de Salud, instancia cumbre sectorial de la sociedad civil que acuerde y ratifique propuestas a lo largo de los distintos momentos constitutivos del desarrollo del proceso político que constituye la reforma y que fueron ya detallados en anterior apartado de este trabajo.

4. Los acuerdos ratificados por el Congreso Cindadano para la Reforma de Salud deberán asumirse como Pactos de Sociedad Civil a ser convertidos en Pactos de Estado-Nación, producto de su presentación y negociación con las instancias ministeriales, a resultas de lo cual podrá tomarse iniciativa de ley, cuando logren alcanzarse los consensos suficientes para poder ser adoptados como tales.

5. Finalmente, el Comité de Consulta Ciudadana también podrá convocar al Congreso Ciudadano para el ejercicio del referéndum ${ }^{58}$ cuando las disposiciones normativas y/o actos administrativos de la carte-

615

Relorma sanitaria: fundamentalismo neoliberal auloritario o democratización inaplazable 
ra de Estado, a propósito de la reforma sectorial, se estime que requieran de ratificación o desaprobación por voto ciudadano directo.

\section{Objetivos que se pretenden alcanzar con la propuesta de cogestión de la reforma}

El objetivo general tiene que ser viabilizar el consenso en la formulación de la política de salud sobre la cual descanse la reforma sectorial, de manera que pueda garantizarse gobernabilidad en la adopción de la primera y en la implementación de la segunda. Junto a él, al menos cinco objetivos específicos resultan claramente identificables:

1. Articular en una sola todas las iniciativas provinientes de la sociedad civil, a fin de vertebrar una propuesta coherente de política de salud que sirva de fundamento a la reforma sectorial.

2. Crear las instancias organizativas necesarias (Comité de Consulta Ciudadana y Congreso de Consulta Ciudadana para la Reforma de Salud) para la gestión política que desde la sociedad civil se haría con el fin de dar salida y cause al ejercicio de democracia participativa requerido por el proceso político generado a raíz de la reforma.

3. Incorporar el plebiscito, referéndum y la iniciativa ciudadana en la instrumentación del ejercicio de democracia participativa requerido para una formulación y adopción de la política y reforma sanitarias que gocen del consenso y de la gobernabilidad necesarias.

4. Crear un clima de opinión favorable entre los actores sociales gubernamentales involucrados en el proceso político generado por la reforma sectorial, en el sentido de que la efectiva rectoría institucional pasa por reunir un liderazgo y adecuado manejo de la coyuntura como condiciones de viabilidad para la misma a fin de poderse así cumplir adecuadamente (no autoritariamente) con la función de dirección y conducción que supone la cogestión del proceso de reforma.

5. Llamar la atención de la Organización Panamericana de la Salud (OPS) para hacerle notar que sus próximas acciones de cooperación técnica en apoyo al proceso de reforma sectorial, pasarán necesariamente por insistir más vigorosamente en que el Ministerio de Salud advierta que la participación social en la reforma debe ser un hecho irreversible por parte de los diferentes organismos que conforman el sector salud y que la rectoría bien entendida demanda una actitud contraria a todo aquello que la subyrugue. 
La difusión y promoción de esta propuesta en tanto marco de referencia conceptual-operativo del papel de la sociedad civil en el proceso de reforma, daría inicio al momento mismo de terminada su presentación en este documento, poniéndola en circulación para su conocimiento, particularmente por los actores sectoriales relevantes y sociedad civil en general.

De allí en adelante corresponderá a los mismos actores sociales activar el proceso que conduzca a la implementación de la propuesta recomendándo los meses inmediatos anteriores y posteriores a la toma de posesión del nuevo gobierno para lograra la mayor parte de su ejecución.

Ciertamente ese es el período de formulación y negociación de compromisos políticos en donde la sociedad civil debe aprovechar las obligadas señales positivas de búsqueda y construcción de consensos nacionales que las fuerzas políticas envían a la sociedad. Tomarles la palabra y comprometer la agenda política con la inclusión de este tema es una tarea fundamental en el presente y futuro inmediato.

\section{Impacto de la propuesta sobre la vida nacional}

El impacto de la propuesta sobre la reforma en su conjunto puede haber quedado advertido en lo escrito hasta este punto. Quizás convendría destacar más bien su impacto en la vida política nacional en tanto que su realización es "poner a la prueba de fuego" al país en su condición de Estado democrático.

Ciertamente, habrá que decir que El Salvador nunca ha tenido una sociedad civil fuerte, apenas son modestos los logros más recientes alcanzados después de los Acuerdos de Paz y aún esos están seriamente amenazados de reversión. A pesar de ello, y quizás hasta en razón de ello, debemos comprometer más nuestro ingenio y habilidad política para producir y ejecutar propuestas que busquen con audacia que los temas de interés nacional sean resueltos con la negociación como forma privilegiada de dirimir las discrepancias.

En todo esto, es clara la importancia del Estado y de sus aparatos de gobierno a fin de abrir espacios a la participación de la sociedad civil o escamotearla para mostrarla en una versión de democracia a cuentagotas. Sólo de la primera forma, El Salvador enfrentará con mayores probabilidades de éxito el reto de revertir en definitiva los 
imbalances de poder que le han impedido construir la sociedad que siempre hemos merecido.

Ciertamente, esta propuesta podría equivaler al establecimiento de un Parlamento Ciudadano que, aún cuando hoy por hoy, apenas tomaría cuerpo en distintos procesos de consulta, evoca y apunta -a pesar de su actual falta de institucionalidad- a vislumbrar ese Parlamento como contrapunto de la Asamblea Legislativa ${ }^{59}$.

Sin ser contrafigura una de la otra, serían sin duda alguna referentes de la democracia participativa y democracia representativa respectivamente, que permitirían a los ciudadanos hacer gobierno en tanto gestores de compromisos (y veladores de su cumplimiento) a fin de ser presentados ante la Asamblea Legislativa para que tomen cuerpo y fuerza de ley. En resumen, se trata de ir estableciendo en El Salvador y como parte de su cotidianidad, cambios en la forma de gobierno y de representar, en fin, nuevas formas de hacer buena política para evitar, en este particular caso, que la salud sea convertida en el menos público de los bienes que podemos disfrutar.

\section{Impacto de la propuesta en el personal del Ministerio de Salud}

En los trabajadores del Ministerio, sea cual sea el nivel organizacional mintzberiano que ocupen dentro de él, el impacto de la propuesta les permitirá fundamentalmente la posibilidad de arribar a la correcta comprensión y aplicación del concepto de rectoría con lo que estarían en condiciones de contribuir al ejercicio pleno - no tutelado- de la participación social ciudadana en el proceso de reforma.

Particularmente a nivel de línea media (Gerencia de SIBASI/Equipos Técnicos de Zona) y núcleo operacional (personal de dirección y personal asistencial de hospitales y unidades de salud) permitirá a quienes laboran en ellos salir de la encrucijada en la que los pone el mismo marco teórico-conceptual de los SIBASI al que se le une el Código de Salud actualmente en anteproyecto: les piden el fomento de la participación social para cooptarla, les piden en realidad de la participación social un atisbo para después legitimar lo actuado en pro de la reforma neoliberal privatizadora que se desea implantar. 
De hecho, entendiendo correctamente el ejercicio de la rectoría sanitaria, el personal del Ministerio no tendrá que recurrir autoritariamente a su condición de "pertenecer al Ministerio" para investirse de un poder inapelable que coaccione al movimiento ciudadano que reivindicando su derecho a la salud demande una orientación y proceder apegado a la equidad y la justicia a favor de respetar este derecho.

El Ministerio de Salud, particularmente su ápice estratégico (Despacho Ministerial, Direcciones de Planificación, Regulación, Aseguramiento de la Calidad y de Administración Financiera junto a las unidades asesoras) parece haber olvidado que en El Salvador posterior al conflicto, la participación social, por muy local que sea su escenario, no es nada raro que incluya entre sus actores (institucionales o no) a ciudadanos fogueados como líderes que gozan de empoderamiento y prestigio en sus comunidades. Se olvida que incluso las comunidades mismas han ejercido (a nivel local y hasta nacional) el liderazgo y la habilidad en el manejo de coyunturas que el Ministerio no ha dado muestras de poseer en el ejercicio de las funciones de dirección y conducción que de ser rector se esperaría tuviera.

También son actores sociales que están en condiciones de hacer de la contraloría social un ejercicio genuino de velar por compromisos adquiridos y por gestiones transparentes, de forma que sabrán tomarles la palabra a quienes actuando como autoridad sanitaria local tendrían que rendir cuentas por lo actuado.

Este escenario local y nacional difícilmente resulta improbable, por lo que si se va a enarbolar la participación y la contraloría, más vale que se abandonen las posturas propias del fundamentalismo neoliberal autoritario para dar paso a lo que una rectoría sanitaria bien entendida requiere en su ejercicio. De ahí que gerentes de SIBASI, junto a sus Comités de Gestión y Equipos Técnicos de zona, tienen que advertir que en sus Comités de Consulta Social está puesta la oportunidad y el desafío de dejar el autoritarismo a un lado y optar por un correcto ejercicio de rectoría a pesar del mismo Ministerio.

Es necesario reflexionar también sobre el caso del personal de los hospitales, que, dentro de la red de establecimientos, constituyen los llamados Centros Nacionales de Referencia, pues en ellos trabajan como parte del núcleo de operaciones un grupo importante de perso-

Relorma sanilaria: fundamentalismo neoliberal autorilario o democratización inaplazable 
nal sanitario especializado, particularmente médicos y enfermeras, cuyas actividades laborales son de complejidad tal que requieren de una formación especial, generalmente adquirida en centros de educación superior, de manera que las normas de ejecución de su trabajo (protocolos de diagnósitco y tratamiento) vienen más del paradigma científico al que hayan sido expuestos en su formación de especialistas que de la formalización intentada por analistas de operaciones sobre el trabajo médico con una visión estrictamente gerencial.

Por lo tanto, el profesional tiene un cierto control sobre su propio trabajo, lo que implica una relativa independencia en la forma en que cumple sus tareas de categorizar la necesidad del usuario (diagnóstico) e indicar y aplicar el programa terapéutico que corresponda.

Todo lo expuesto hace más comprensible que, sobre todo en estructuras hospitalarias una parte del poder anide justamente en estos profesionales especializados que constituyen el núcleo de operaciones de su estructura. Ello, además, permite entender mejor por qué en estas estructuras hospitalarias también existe un fenómeno particular en el cual el médico propende hacia una mayor identificación con su profesión que con la organización en la que trabaja, lo cual es claramente percibido por los directores de los hospitales llegando a partir de ello al establecimiento de una fuerte tensión entre la dirección del establecimiento y los profesionales que allí laboran, en momentos de coyunturas particulares, como sería justamente la de una reforma sanitaria.

En este escenario, el personal hospitalario especializado resulta ser, por razones de su mismo trabajo, un observador prontamente atento al rumbo que puede tomar el sistema de salud a partir de la orientación neoliberal de la pretendida reforma a ser impulsada por el Ministerio. De forma precoz advierte cuando nuevas disposiciones administrativas desarrolladas en cada hospital resultan premonitorias de una orientación privatizadora de los servicios que brinda, y en razón de ello, ha tenido que recurrir en repetidas ocasiones a la huelga como instrumento extremo (pero civilizado) de presión para frenar un irresponsable proceso de privatización de una importante cantidad de servicios de salud.

Desde esta perspectiva, es justo el disenso de los médicos frente a las tendencias hacia la privatización masiva del sector salud; sin embargo, mucho ayudará a los médicos en el diseño de cualquier plan 
futuro para resistir la privatización, tener una relación más fluida con la sociedad civil, de la que forman parte (a ello conduciría la propuesta) la que contribuiría además a privilegiar la racionalidad, la prudencia y el sentido ético indispensables para reconocer la mejor manera de encontrar una buena solución para convertir las fuerzas que ahora son de enfermedad $y$ muerte en otras que sean de salud y vida ${ }^{60}$. Asumiendo la propuesta de cogestión de la reforma el gremio médico encontraría los espacios y oportunidades para mostrar su voluntad política y su genuina preocupación por discutir sobre la reforma sanitaria que garantice la necesaria orientación estatal hacia la consecución del bien común y el respeto a derechos fundamentales entre ellos el de la salud ${ }^{61}$, y daría salida inteligente a la conflictividad latente en el campo sanitario, lo que de suyo sería una importante contribución preventiva de niveles superiores de conflictividad ${ }^{62}$, dado que la confrontación continua tiene el grave riesgo de llevar al país por el deslizadero de la violencia social.

Es un hecho que el conflicto, contrario a lo que algunos se empecinan a divulgar, es inherente a la dinámica de la realidad social, el desafío está entonces en enfrentarlo inteligentemente antes que satanizar a sus protagonistas. Entiéndasenos bien: No instigamos el conflicto, simplemente señalamos un atributo inmanente a la realidad social: su conflictividad.

De adherirse entonces al esfuerzo de cogestión de la reforma que ha sido propuesto, los médicos estarán en el sitio idóneo para construir amplias alianzas con sectores y organizaciones sociales, plataforma desde la cual difícilmente podrían dar razón a la retórica gubernamental que no tarda en señalar que el movimiento médico tiene por motivación real de su protesta la electoral y que responde en tal sentido a intereses políticos de izquierda ${ }^{63}$.

En este contexto, lo que se pretende con este artículo es contribuir a la reflexión confiados en que el esclarecimiento de los problemas desde la óptica de salud permita que las personas vinculadas a este sector movilicen nuevas energías y den un nuevo aliento a quienes han perdido la esperanza de influir en nuestro futuro. 
1. Selva Sutter, E. A. De política y de políticas de salud. Publicaciones del Departamento de Salud Pública, Universidad Centroamericana José Simeón Cañas. San Salvador, agosto de 2003. $17 \mathrm{pp}$.

2. Walt, G. Health Policy. An introduction to process and power. Witwatersand University Press, Johannesburgo. 7 ed. Books London and New Jersey. 1994.

"An Introduction: policy analisys in the Policy-Making process", PP. 15-19, en Dunn, W.N., Public Policy Analysis, 2da. Edic., Prentice Hall, New Jersey, 1990.

3. Selva Sutter, E.A. Epidemiologia socionatural. Su interacción con un nuevo concepto sobre la calidad de los procesos de salud/enfermedad. Publicaciones del Departamento de Salud Pública, Universidad Centroamericana José Simeón Cañas. San Salvador 1992. Revisado: 2003.

4. Ibid.

5. Selva Sutter, E.A. "Reforma de salud reivindicativa democrática y con enfoque público". ECA, 651-652, enero-febrero de 2003, Págs. 21-42.

6. Selva Sutter, E.A. "Tropelías a la salud pública en tiempos de la globalización". Estudios Centroamericanos (ECA), No. 648. Págs. 958-968

"Al oído de aquellos interesados en la reforma de salud". ECA, Nos. 619620. Págs. 573-598

. Historias prohibidas de la reforma de salud en El Salvador. Publicación del Departamento de Salud Pública. Marzo de 2002.

7. Ministerio de Salud Pública y Asistencia Social. Programa de modernización en salud. Sistema sanitario. San Salvador, diciembre de 1997.

8. Consejo de Reforma del Sector Salud. Propuesta de reforma integral de salud. San Salvador, 15 de diciembre de 2000.

9. Originadas por el Sindicato de Médicos Trabajadores del Seguro Social (SIMETRISSS), el Colegio Médico, PROSAMI, FMLN/USC, la Sociedad de Residentes del ISSS, Mesa 13 del Plan de Nación, Sanidad Militar, Sindicato de Trabajadores del Seguro Social (STISSS), Comisión Nacional de Salud (CONASA), BN/BID/AID y Provida.

10. En este sentido, son particularmente importantes los artículos de Selva Sutter en los que quedan demostrados minuciosamente los graves peligros que tal propuesta encierra.

11. Consejo de Reforma del Sector Salud. Op. cit., p. 48.

12. "El desafío de la alternancia en el poder". ECA, No. 656, junio de 2003, pp. 513529.

13. Ibídem. Los paréntesis son nuestros.

14. Artiga-González, A. "El autoritarismo que se niega a morir y que prefiere acabar con la democratización política". ECA, No. 656, junio 2003. Pp. 531-540.

15. Selva Sutter, E.A. "La descentralización y la reforma de salud neoliberal". ECA, No. 660. Octubre de 2003. Págs. 1029-1047.

. "Sistema de salud mixto público y privado neoliberal, quizás abuso, engaño o torpeza, pero siempre privatización". Inédito.

16. Gracia, D. "La rectoría de la salud”. OPS/OMS. 1995.

17. Ibidem. 
18. Baño, R. "Primer seminario sobre participación ciudadana y evaluación de políticas públicas”. Santiago de Chile. Septiembre 1996-enero 1997. FLACSO-Chile.

19. Ibidem.

20. En el país, la condición de experto no ha sido adjudicada siempre con la rigurosidad deseada según estándares académicos habitualmente exigidos en otras latitudes.

21. Correa, E. "Participación ciudadana y gobernabilidad". En Primer Seminario Conceptual sobre participación ciudadana y gobernabilidad, Op. cit, p. 30.

22. Poulanzas, N. Estado, poder y clases sociales. Siglo XXI Editores, México. 1978.

23. Portelli, H. Gramsci y el bloque bistórico. Siglo XXI Editores, México 1978.

Althusser, L. "Ideología y aparatos ideológicos del Estado". En El Estado, selección de N. Mariscal. UCA Editoreś, San Salvador. 1985.

24. Ibidem.

25. En el sentido gramsciano del término.

26. Banco Mundial Informe sobre el desarrollo mundial 1993. Invertir en Salud. Oxford University Press. Washington, DC. Julio 1993. 335 PP.

27. Una revisión particularmente detallada de esto es la que realizó Selva Sutter en los artículos citados.

28. Ibisate, F.J. "Neoliberalismo y globalización". ECA, No. 600:893-908. Octubre 1998.

29. "Una oportunidad para reflexionar sobre la libertad del mercado". ECA, Editorial. No. 600, pp. 895-896. Octubre 1998.

30. Foucault, M. Vigilar y castigar. Siglo XXI Editores. México, 1983.

31. Ibidem.

32. Alvarenga Venutolo, P. Cultura y ética de la violencia: El Salvador 1880-1932. EDUCA. San José. 1996. 372 Págs.

33. Mintzberg, H. "La burocracia profesional". En La estructuración de las organizaciones. Ariel. España. 1990. Págs. 393-425.

34. Ministerio de Salud Pública y Asistencia Social. Anteproyecto Código de Salud. Septiembre 2003, República de El Salvador. 98 págs.

35. Ibidem. Cap. III Sector Salud. Arts. 8 al 10.

36. Ibidem. Art. 9, literal i)

37. Ibidem, Cap. IV, Art. 11.

38. Selva Sutter, E.A. "Sistema de salud mixto público y privado neoliberal, quizás abuso, engaño o torpeza, pero siempre privatización". Pendiente de publicación.

39. "Anteproyecto Código de Salud". Op. Cit. Cap. IV, Título II, Arts. 12 y 13.

40. Ibidem. Título III, Arts. 14 a 16.

41. Ibidem. Art. 16.

42. Ministerio de Salud Pública y Asistencia Social. Sistemas Básicos de Salud Integral (SIBASI): Marco conceptual y operativo. Versión revisada. San Salvador, El Salvador, septiembre de 2001. 36 págs.

43. Ibídem, pág. 5.

44. Ibídem. Pág. 10.

45. Ibidem. Pág. 14.

46. Ibídem. Pág. 15.

47. Ibídem. Pág. 90.

48. Ibídem. Pág. 19.

49. Ibídem. Pág. 19-20.

Relormo sanitaria: tundamentalismo neoliberal autoritario o democratización inaplazable 
50. De Roux, G. "Participación y cogestión de la salud". Educación Médica y Salud, Vol. 27, No. 1 (enero/marzo 1993): 50-60.

51. Pero con propósitos totalmente opuestos a la idea de Johann Peter Frank (17451821), que a pesar de ser identificada por su carácter autoritario y paternalista se apegaba a la idea de instrumentar y hacer cumplir regulaciones sanitarias, procurar la prosperidad de la población y mantener el orden público como métodos para mejorar la salud. Cfr. Rosen, G., De la policía médica a la medicina social. Ensayo sobre la bistoria de la atención a la salud. Siglo XXI Editores, México. 1985. Pág. 379.

52. Ministerio de Salud Pública y Asistencia Social. Anteproyecto Código de Salud. Op. Cit. Pág. 5.

53. Ibidem, Título XX, Art. 358-9.

54. Sánchez Viesca, A. et al. Construcción democrática y equidad en salud. Grupo de investigadores centroamericanos en Políticas, Sistemas y Servicios de Salud (GRISSAC) s.l., s.f.

55. Quizá el único antecedente en la historia más reciente sea el ejercicio de participación ciudadana que actores sociales de la sociedad civil articularon en 1991 y 1992, en lo que se llamó "Concertación de Salud" que pretendió formular una propuesta ante el Ministerio de Salud Pública a fin de salvaguardar, una vez fuesen alcanzados los Acuerdos de Paz, la experiencia organizativa, de recursos humanos y de prestación de servicios con la que se había venido trabajando durante los años de la guerra en las zonas llamadas exconflictivas.

56. Excluidos el BM, el BID y la AID, dada su condición de agencias bi o multilaterales propulsoras de la orientación neoliberal

57. Plesbicito: Resolución tomada por un pueblo a pluralidad de votos. Aun cuando suele estar referido como una iniciativa originada por los poderes públicos no resulta privativa de ellos. Su propósito es someter a voto popular directo la aprobación o rechazo de temas de interés nacional

58. Aun cuando más estrictamente referido como procedimiento jurídico que someta a voto popular directo leyes cuya aprobación o rechazo es requerido, también es una oportunidad de hacer saber a quienes han sido elegidos para tomar decisiones, los puntos de vista de la población sobre asuntos controvertidos.

59. Cuenca, B. “Hacia un Parlamento Ciudadano?”. Suplemento Especial "Agenda Nuevo Siglo" de la Revista Tendencias. Oct. 1998.

60. Universidad Centroamericana José Simeón Cañas. Pronunciamiento "Un llamado a la sensatez y a la ética". Estudios Centroamericanos ECA 649-650, 2002.

61. Ídem.

62. Russbach, R.: "Conflictos armados, prevención y salud pública". Revista Internacional de la Cruz Roja Internacional. No. 833, pp 85-102. Marzo 1999. http:// www.icrc.org/icrcspa.nsf (01/02/03)

63. Criterios éticos para reformar la salud". ECA, No. 651-652. 2003 